\section{Difficulties of peace-building in Nepal}

S onal Singh ${ }^{1}$ describes how political $S$ conflict has affected people's health in Nepal, concluding that health care professionals can play an important role in peace-building efforts. However, this is not as easy as it sounds.

In December 2002, we organized a 2-day meeting in the central developing region of Nepal, which was attended by health directors from 29 of the 33 subhealth posts (the local medical clinics in Nepal). During the meeting, we used group discussion to identify the difficulties encountered under the conflict. The participants reported their suffering at the hands of both the Maoists and government security forces, mentioning that they are often caught in the crossfire between the 2 opposing sides. The Maoists regard health care workers with suspicion, viewing them as supporters of other political parties or spies for the government. Conversely, the government security forces suspect the health care workers of being Maoist supporters.

All the participants told us that the frequent misbehaviour of both parties has caused mental trauma. Health care professionals should play an important role in peace-building, but how much of themselves do they have to sacrifice in the course of doing so?

\section{Amod K. Poudyal \\ Masamine Jimba \\ Susumu Wakai}

Department of International Community Health

Graduate School of Medicine

The University of Tokyo

Tokyo, Japan

Acknowledgements: We thank Naresh P. KC and Ram C. Silwal for their fieldwork related to this letter, and Krishna C. Poudel for his support in writing the letter.

\section{Reference}

1. Singh S. Impact of long-term political conflict on population health in Nepal. CMA7 2004;171 (12):1499-501.

DOI:10.1503/cmaj.1050013

\section{[The author responds:]}

Tagree with Amod Poudyal and colleagues that health care professionals face challenges if they are to play an active role in peace-building efforts in Nepal, as I suggested in my article. ${ }^{1}$ However, they must rise to this challenge, as they have already been drawn into the conflict. The government has issued directives to all health care professionals and institutions stating that if they provide treatment without appropriate notification, they will be regarded as supporters of terrorists and be prosecuted according to the Terrorist and Disruptive Activities Ordinance, 2001. ${ }^{2}$ This puts medical professionals in an impossible situation. During the ongoing conflict, they are at risk of encountering armed groups demanding treatment for their wounded; however, provision of such treatment might lead to subsequent prosecution. The Maoists have similarly targeted health care workers.

Despite these challenges, there is still room for continuation of healthrelated projects, through an approach known as "conflict-sensitive development" - development that is sensitive to the conflict environments in which it occurs. ${ }^{3}$ There is a need for transitional programs in conflict areas that can adapt to the rapidly changing environment, as well as greater involvement of humanitarian agencies with experience in conflict settings, such as Médecins Sans Frontières. A participatory role in development for neutral local agencies and increasing community participation are essential.

Ultimately, how much of themselves health care workers must sacrifice will depend on individual choices and the local context. It is their re- 
sponse to these challenges that may determine the future of Nepal in this time of crisis.

\section{Sonal Singh}

Department of Medicine

Unity Health System

Rochester, NY

\section{References}

1. Singh S. Impact of long-term political conflict on population health in Nepal. CMA7 2004;171 (12): 1499-501.

2. Sharma GK, Osti B, Sharma B. Physicians persecuted for ethical practice in Nepal. Lancet 2002:359(9316):1519.

3. Singh S. Nepal's war and conflict-sensitive development. PLoS Med 2005;2(1):e29. Available: http ://medicine.plosjournals.org/perlserv/?request=get -document\&doi=10.1371/journal.pmed.0020029 (accessed 2005 Apr 26).

DOI:10.1503/cmaj.1050046

\section{Summary Basis of Decision in context}

Tn their analysis of Health Canada's Summary Basis of Decision (SBD) initiative, Joel Lexchin and Barbara Mintzes $^{1}$ raise important issues about transparency, but they do not discuss the unique Canadian legal context within which manufacturers submit their information for review.

The confidentiality of drug submissions is anchored in Canadian common law, federal statutes and international trade obligations. Drug manufacturers can usually argue successfully that data kept in trade confidence by the manufacturer and submitted to Health Canada in confidence are excluded from disclosure under the Access to Information Act. The recent Federal Court of Canada decision in the Singulair case ${ }^{2}$ may impose further limits on the release of review information under access legislation. In the interests of public disclosure, Health Canada has appealed that decision.

With some exceptions, the North American Free Trade Agreement and the World Trade Organization's Agreement on Trade-Related Aspects of Intellectual Property Rights also require member countries, including Canada, to take steps to protect data filed with a national authority as a condition for market authorization.

Lexchin and Mintzes contend that the US Food and Drug Administration (FDA) routinely posts detailed information submitted by the drug company, along with FDA reviewers' analyses. In fact, the FDA ceased publication of Summary Basis of Approval documents in 1994, opting to publish hundreds of pages of review information, with confidential commercial information severed. The FDA was subsequently criticized by the US inspector general for not providing summary information; ${ }^{3}$ that criticism was based on concerns about the readability of the full reviews for many segments of the public.

The SBD provides concise public information on the quality, clinical efficacy and safety elements of a drug submission, including summaries of clinical trial design and premarketing adverse events. Our consultations indicate that this is a major step forward, particularly for consumer associations and health care providers.

\section{Diane Gorman}

Assistant Deputy Minister

Health Products and Food Branch

Health Canada

Ottawa, Ont.

\section{References}

1. Lexchin J, Mintzes B. Transparency in drug regulation: Mirage or oasis? [editorial]. CMA7 2004; 171(11):1363-5.

2. Merck Frosst Canada \& Co. v. Canada (Minister of Healtb), [2004] F.C. 959, Harrington J.

3. Rehnquist J. FDA's review process for new drug applications: a management review. Bethesda (MD): Department of Health and Human Services, Office of Inspector General; 2003. Available: http://oig.hhs.gov/oei/reports/oei-01-0100590.pdf (accessed 2005 Jan 28).

DOI:10.1503/cmaj.1041766

\section{[The authors respond:]}

$\mathrm{D}$ iane Gorman maintains that Canadian federal statutes prevent Health Canada from releasing clinical information about safety and efficacy without the consent of the company submitting the data. In doing so, she ignores a section of the Access to Information Act that allows the release of such information if it "would be in the public interest as it relates to public health." ${ }^{1}$ To our knowledge, Health Canada has never chosen to use this clause to disclose information.

Health Canada's Science Advisory Board examined whether the North American Free Trade Agreement created a barrier to disclosure of premarket clinical trial data and concluded that "Measures to require transparency for the protection of the public are not a violation of this treaty obligation."

Ms. Gorman points out that the FDA stopped posting Summary Basis of Approval documents in 1994, but that was because of the workload involved, not because of the North American Free Trade Agreement. The redacted review information still contains detailed reports of methods and results of the clinical trials that the companies performed. As we pointed out in our commentary, ${ }^{3}$ that information is not available in the SBD.

Finally, Ms. Gorman says that Health Canada's consultations show that consumer associations and health care providers find the SBD a major step forward. She fails to mention the statement issued by those attending the Health Canada SBD consultation, who endorsed the goal of transparency but stated firmly that "the model for a Summary Basis of Decision put forward at this consultation does not meet these common goals." Groups signing the statement included the Canadian Organization for Rare Diseases, Doctors for Research Integrity, the Hospital Employees Union, the Society for Diabetic Rights, Women and Health Protection, PharmaWatch and the BC Persons With AIDS Society.

\section{Joel Lexchin}

Associate Professor

Department of Family and Community

Medicine

University of Toronto

Toronto, Ont.

\section{Barbara Mintzes}

Postdoctoral Fellow

Department of Pharmacology and

Therapeutics

University of British Columbia

Vancouver, BC 